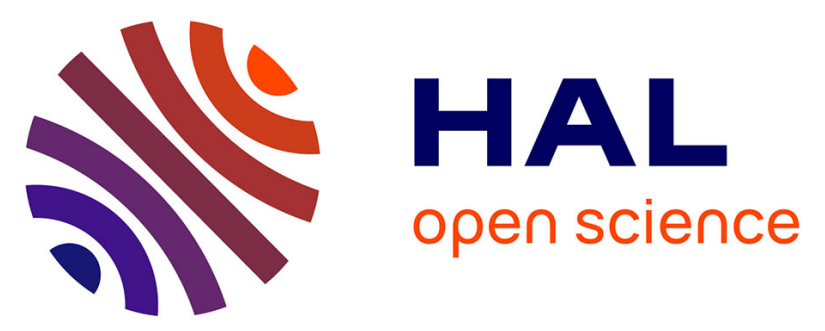

\title{
Spectral characterization of the fluorescent components present in humic substances, fulvic acid and humic acid mixed with pure benzo( a )pyrene solution
}

Rawa El Fallah, Régis Rouillon, Florence Vouve

\section{- To cite this version:}

Rawa El Fallah, Régis Rouillon, Florence Vouve. Spectral characterization of the fluorescent components present in humic substances, fulvic acid and humic acid mixed with pure benzo( a )pyrene solution. Spectrochimica Acta Part A: Molecular and Biomolecular Spectroscopy [1994-..], 2018, 199, pp.71-79. 10.1016/j.saa.2018.03.030 . hal-01770449

HAL Id: hal-01770449

https://hal-univ-perp.archives-ouvertes.fr/hal-01770449

Submitted on 18 Jul 2018

HAL is a multi-disciplinary open access archive for the deposit and dissemination of scientific research documents, whether they are published or not. The documents may come from teaching and research institutions in France or abroad, or from public or private research centers.
L'archive ouverte pluridisciplinaire HAL, est destinée au dépôt et à la diffusion de documents scientifiques de niveau recherche, publiés ou non, émanant des établissements d'enseignement et de recherche français ou étrangers, des laboratoires publics ou privés. 


\title{
Spectral characterization of the fluorescent components present in humic substances, fulvic acid and humic acid mixed with pure benzo $(a)$ pyrene solution
}

\author{
Rawa El Fallah, Régis Rouillon, Florence Vouvé* \\ Univ. Perpignan Via Domitia, Biocapteurs-Analyses-Environnement, 66860 Perpignan, France \\ Laboratoire de Biodiversité et Biotechnologies Microbiennes, USR 3579 Sorbonne Universités (UPMC) Paris 6 et CNRS Observatoire Océanologique, 66650 Banyuls-sur-Mer, France
}

Keywords:

Fluorescent excitation-emission matrices PARAFAC

Humic substances

Fulvic acid

Humic acid

Benzo(a)pyrene

\begin{abstract}
A B S T R A C T
The fate of benzo( $a$ )pyrene ( $\mathrm{BaP})$, a ubiquitous contaminant reported to be persistent in the environment, is largely controlled by its interactions with the soil organic matter. In the present study, the spectral characteristics of fluorophores present in the physical fractions of the soil organic matter were investigated in the presence of pure BaP solution. After extraction of humic substances (HSs), and their fractionation into fluvic acid (FA) and humic acid (HA), two fluorescent compounds $\left(C_{1}\right.$ and $\left.C_{2}\right)$ were identified and characterized in each physical soil fraction, by means of fluorescence excitation-emission matrices (FEEMs) and Parallel Factor Analysis (PARAFAC). Then, to each type of fraction having similar DOC content, was added an increasing volume of pure BaP solution in attempt to assess the behavior of BaP with the fluorophores present in each one. The application of FEEMs-PARAFAC method validated a three-component model that consisted of the two resulted fluorophores from HSs, FA and $\mathrm{HA}\left(\mathrm{C}_{1}\right.$ and $\left.\mathrm{C}_{2}\right)$ and a BaP-like fluorophore $\left(\mathrm{C}_{3}\right)$. Spectral modifications were noted for components $C_{2}$ HSs ( $C_{2}$ in humic substances fraction) ( $\lambda$ ex/ $\lambda$ em: $420 / 490-520 \mathrm{~nm}$ ), $C_{2}$ FA ( $C_{2}$ in fulvic

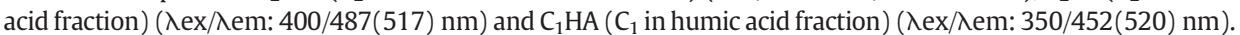
We explored the impact of increasing the volume of the added pure BaP solution on the scores of the fluorophores present in the soil fractions. It was found that the scores of $\mathrm{C}_{2} \mathrm{HSs}, \mathrm{C}_{2} \mathrm{FA}$, and $\mathrm{C}_{1} \mathrm{HA}$ increased when the volume of the added pure BaP solution increased. Superposition of the excitation spectra of these fluorophores with the emission spectrum of BaP showed significant overlaps that might explain the observed interactions between BaP and the fluorescent compounds present in SOM physical fractions.
\end{abstract}

\section{Introduction}

Polycyclic aromatic hydrocarbons (PAHs), which are compounds formed by the fusion of benzene rings consisting only of carbon and hydrogen, are important environmental pollutants of big concern because many of them are carcinogens and mutagens [1,2]. They originate from a variety of natural and anthropogenic sources. Particular attention has been made on the PAHs with high-molecular mass, such as benzo( $a$ ) pyrene $(\mathrm{BaP})$, for their toxicological aspect $[3,4]$. BaP was reported as an indicator of the presence of other PAHs in different environmental compartments (water, soil, sediments) [5]. It is persistent in the environment, part because of its low bioavailability and because of its strong adsorption onto the soil organic matter (SOM) [6]. This strong interaction with SOM makes it un-degradable and unavailable resulting in soil contamination problems.

\footnotetext{
* Corresponding author at: Univ. Perpignan Via Domitia, Biocapteurs-AnalysesEnvironnement, 66860 Perpignan, France.

E-mail address: vouve@univ-perp.fr (F. Vouvé).
}

Soil organic matter, a key factor in the sustainability of soil, is composed mainly of humic substances (HSs) and nonhumic substances $[7,8]$. HSs are a complex mixture of several heterogenous aggregates [9]. HSs can be fractioned into humin, a black colored fraction insoluble in water at any $\mathrm{pH}$; the humic acid (HA), black or brown, soluble in basic medium and insoluble in acidic $\mathrm{pH}(<2)$, and the fulvic acid (FA), yellowish and soluble in water at any $\mathrm{pH}$ [10]. HA is composed of natural polydispersed polyelectrolyte bio-colloids [11,12] and are characterized by the presence of many functional groups such as carboxylic acids, phenols and amines [9]. FA is characterized by small molecular size and large carboxyl group [13]. HA and FA contain also quinone and semi-quinone function groups $[14,15]$. Studies have shown that soil organic matter is predominant in the sorption of PAHs; it largely controls the fate of these pollutants [16]. PAHs were found to associate with the hydrophobic regions of soil organic matter because they have low solubility in water [17]. Binding affinity, expressed as the partition coefficient (Koc), was found correlated with aromaticity of the organic matter [18]. Thus, the hydrophobicity of the pollutant and the quality of the soil organic matter determine the nature of the interactions 
occurring between them and define the extent of pollutant's bioavailability and toxicity $[19,20]$. Since SOM has a complex structure that is difficult to characterize, studies have used the physico-chemical properties such as the spectral properties to characterize and define HSs, HA and FA [21], and particularly the fluorescence spectroscopy method [22].

The fluorescence spectroscopy, especially the development of fluorescent excitation-emission matrixes (FEEMs) [23,24], have been widely used over the last decade to obtain information on the fluorescent characteristics of organic matter, to determine its origin and to assess its quality in different ecosystems [25-28]. The popularity of this method is due to the fact that it is a highly sensitive and nondestructive method that does not require a large amount of preparation time, the fast data acquisition and the large amount of information on the molecular structure and chemical properties of natural organic matter it provides [29-33]. However, in order to interpret and decompose the FEEMs, chemometric algorithms such as Parallel Factor Analysis (CP/ PARAFAC) are frequently used [34-38]. PARAFAC is an advanced multivariate statistical technique that has been employed in the area of analytical and environmental chemistry; it is often utilized for the analysis of the three-way data sets [39] such as sample with x excitation wavelength y emission wavelength resulted from FEEMs [40-42]. It can identify and quantify the components of a multicomponent system and is able to extract their relative concentration and their pure excitation and emission spectra $[43,44]$. The combination of FEEMs with the PARAFAC algorithm is widely used to characterize the organic matter from terrestrial origin $[22,37,45]$, aquatic origin $[32,42,46]$. Several authors have also proven the efficiency of this method to detect PAHs in pure solutions [36], in water samples [34], aqueous motor oil extract and asphalt leachate $[34,36,47]$. This technique makes it possible to observe the qualitative changes in the dissolved organic matter and the different fluorophores present in the tested samples and to detect changes in their fluorescence intensities [42].

FEEMs-PARAFAC method used for detection and quantification of PAHs in environmental matrices $[35,48]$ can also be applied for understanding the interactions between SOM and organic pollutants, such as $\mathrm{BaP}$, which is crucial for assessing their fate in soil environment. Since it is a novel method, there is currently no information available in literature about the effect of $\mathrm{BaP}$ on the spectral characteristics of the fluorophores present in each soil fraction HSs, FA and HA. In this study we combined FEEMs and PARAFAC to (1) determine the spectral characteristics of the fluorophores present in the three physical fractions HSs, FA and HA originating from one soil (2) investigate the effect of the addition of pure BaP solution on the spectral properties of the fluorophores present in HSs, FA, and HA, (3) explore the changes in fluorescence intensities of each fluorophore when the volume of added pure BaP solution increases and (4) clarify the physico-chemical interactions between $\mathrm{BaP}$ and the fluorophores present in each soil fraction.

\section{Materials and Methods}

\subsection{Preparation of Pure BaP Solution}

BaP was purchased from Sigma-Aldrich ( $\geq 96 \%$ ) and was used without further purification. A stock solution of pure BaP $\left(10^{-4} \mathrm{M}\right)$ was produced by weighing the appropriate amount of $\mathrm{BaP}$ and dissolving it in ethanol (Carlo Erba HPLC grade). The stock solution was kept in the dark at $4{ }^{\circ} \mathrm{C}$. A $10^{-5} \mathrm{M}$ BaP solution was prepared in ultra-pure water by diluting the stock solution. This solution was used for the experiments with SOM. Triplet concentrations of $10^{-9} ; 2 \cdot 10^{-9}$ and $5 \cdot 10^{-9} \mathrm{M}$ of pure BaP solutions were also prepared in ultra-pure water to be used as calibration range to be inserted in the PARAFAC models. Ultra-pure water was taken from an Osmodem water purification unit.

\subsection{SOM Extraction and Fractionation}

An acidic brown soil sample was collected between 5 and $20 \mathrm{~cm}$ in depth from a non-polluted remote area of a high mountain (altitude of $1.657 \mathrm{~m}$ ) located in the Pyrénées-Orientales department in southern France $\left(42.52649^{\circ} \mathrm{N} ; 2.12305^{\circ} \mathrm{E}\right)$. SOM was extracted from soil sample in alkaline conditions using an adaptation of Duchaufour and Jacquin [49] protocol, that was later completed by Ratsimbazafy [50]. Briefly, $10 \mathrm{~g}$ aliquots of dried $\left(24 \mathrm{~h}\right.$ at $\left.105^{\circ} \mathrm{C}\right)$ crushed and homogenized soil sieved through $2 \mathrm{~mm}$ mesh, were mixed in PETE bottle with a solution containing $80 \mathrm{~mL}$ of $0.1 \mathrm{M} \mathrm{NaOH}$ (Sigma-Aldrich) and $120 \mathrm{~mL}$ of $0.1 \mathrm{M}$ $\mathrm{Na}_{4} \mathrm{P}_{2} \mathrm{O}_{7}$ (Sigma-Aldrich) to reach a pH around 13. To obtain a correct homogenization, the bottle was put on a rotating agitator in the dark for $24 \mathrm{~h}$. The mixture was then centrifuged at $3600 \mathrm{~g}$ for $20 \mathrm{~min}$. The supernatant thus obtained is the humic substances (HSs) fraction. One part of HSs was stored at room temperature in the dark for analysis. The other part was used to separate the FA and the HA fractions. Concentrated $\mathrm{HCl}$ (37\%, Fulka) was added to HSs, up to $\mathrm{pH}<2$ and the solution was kept in the dark. After $24 \mathrm{~h}$, a precipitate was observed. This solution was centrifuged at $3600 \mathrm{~g}$ for $20 \mathrm{~min}$ to obtain FA fraction (supernatant) and the HA fraction (precipitate). Prior to analysis, HA was solubilized by adding $50 \mathrm{~mL}$ of pure water and agitating till solubilization. The pH of HSs, FA and HA solutions were adjusted to $7.5 \pm 0.1$. Prior to fluorescence measurements, samples were filtered through a $0.45 \mu \mathrm{m}$ filters (PTFE-membrane from Sartorius Stedim Biotech).

\subsection{Sample Preparation}

Reference samples were obtained by preparing five solutions of HSs, FA and HA with different concentrations estimated on their dissolved organic carbon (DOC) contents. Concentrations of DOC were determined using Shimadzu Total Organic Carbon Analyzer $\mathrm{V}_{\mathrm{CSN}}$ (Shimadzu Corp., Kyoto, Japan). Concentrations of HSs samples were 2.71, 4.71, $7.72,15.75,18.22$ and $22.11 \mathrm{mg} \mathrm{DOC} \cdot \mathrm{L}^{-1}$ those of FA were 2.693, $3.209,3.908,7.779$ and $17.48 \mathrm{mg} \mathrm{DOC} \cdot \mathrm{L}^{-1}$ and those of HA samples were $6.788,9.212,13.5,17.2$ and $20.14 \mathrm{mg} \mathrm{DOC} \cdot \mathrm{L}^{-1}$.

As for the experiments with pure BaP, we selected the concentration of each soil fraction having DOC $\pm 7 \mathrm{mg} \cdot \mathrm{L}^{-1}$. For each fraction, triplicates with $3 \mathrm{~mL}$ of solution $\left(\sim 7 \mathrm{mg} \mathrm{DOC} \cdot \mathrm{L}^{-1}\right)$ were prepared. 100,200 and $300 \mu \mathrm{L}$ of pure BaP solution $\left(10^{-5} \mathrm{M}\right)$ was added to the first, the second and the third replicates respectively. The triplicates containing the mixture HSs-BaP, FA-BaP and HA-BaP thus obtained constitute three sets of samples that will be named as $\mathrm{HSs}_{\mathrm{BaP}}, \mathrm{FA}_{\mathrm{BaP}}$ and $\mathrm{HA} \mathrm{BaP}_{\mathrm{Ba}}$.

\subsection{Fluorescence Spectroscopy}

Fluorescence measurements were acquired using a SAFAS flx spectrofluorometer (SAFAS, Monaco) with a Xenon excitation source $(150 \mathrm{~W})$ using $1 \mathrm{~cm} \times 1 \mathrm{~cm}$ quartz cell. All further measurements were performed at room temperature $\left(20^{\circ} \mathrm{C} \pm 2{ }^{\circ} \mathrm{C}\right)$. FEEMs were recorded at $270 \mathrm{~nm} \cdot \mathrm{min}^{-1}$ scan speed. The excitation wavelengths ranged from 200 to $500 \mathrm{~nm}$ at $10 \mathrm{~nm}$ steps. Emission wavelengths ranged from 220 to $800 \mathrm{~nm}$ at $1 \mathrm{~nm}$ interval. Excitation and emission slit widths were set at $10 \mathrm{~nm}$. Raman and Rayleigh diffusions were corrected by subtraction of ultra-pure water FEEM from each FEEMs' sample [31]. We have checked that there were no inner filter effects over each sample. Fluorescence intensities are expressed in arbitrary units (a.u.).

\subsection{Data Analysis}

PARAFAC has been widely described in the literature $[41,42,44,52,55]$ hence, we will briefly describe it. It is applied to a three-way data $X$ that have the trilinear structure such as in the case of FEEM. $\mathrm{X}$, in this case, is a 3-way data cube of dimension $\mathrm{I} \times \mathrm{J} \times \mathrm{K}$ 
and its trilinear decomposition using PARAFAC analysis can be expressed using the following equation

$X_{i, j, k}=\sum_{f=1}^{\mathrm{F}} a_{i, f} b_{j, f} c_{k, f}+\varepsilon_{i, j, k}$

The principle of PARAFAC decomposition is minimizing the sum of square of the residual; $\left(\varepsilon_{\mathrm{ijk}}\right)$ based on a least-squares algorithm which represents some additional residual variation not accounted for by the model. $\mathrm{x}_{\mathrm{ijk}}$ is the intensity of fluorescence for the $i$ th sample at emission wavelength $j$ and excitation wavelength $k . \mathrm{a}_{\mathrm{if}}$ is the relative concentration of analyte $f$ in sample $i$; $b_{\mathrm{jf}}$ is linearly related to the fluorescence intensity of the $f$ th fluorophore at emission wavelength $j, c_{\mathrm{kf}}$ is linearly related to the extinction coefficient of analyte $f$ at excitation wavelength $k$ and $\varepsilon_{\mathrm{ijk}}$ represents the sum of the residuals of the matrices. The PARAFAC model was calculated using a homemade program (progmeef), developed and provided by R. Redon (PROTEE Laboratory, University of Toulon, France) based on Matlab (TM) software. In order to reduce the effect of diffusion and scatter lines, the Rayleigh and Raman scatter were removed according to Zepp [58]. FEEMs were normalized and the data set was fitted with non-negativity constraint and was run for 100 iterations with initialization by random values for all data sets with a convergence criterion of $10^{-6}$. A series of PARAFAC model from two to five components were fitted to the data.

The FEEMs of the reference samples of HSs, FA, and HA were modeled in three separate PARAFAC analyses. The FEEMs of the three sets of triplicates containing the mixture with pure BaP solution $\left(\mathrm{HSS}_{\mathrm{BaP}}\right.$, $\mathrm{FA}_{\mathrm{BaP}}$ and $\mathrm{HA} \mathrm{BaP}_{\mathrm{B}}$ ) were also run by PARAFAC.

The results were validated using core consistency diagnostic (CorConDia) [40]. The similarity coefficient, also known as congruence coefficient $\left(\mathrm{r}_{\mathrm{c}}\right)$ of the computed and the reference two-dimensional fluorescence spectra was calculated according to [59]:

$r_{c}=\frac{\sum a b}{\sqrt{ }\left(\sum a^{2} \sum b^{2}\right)}$

where a and b represent the loadings of computed and reference spectrum respectively. In our study, the computed spectra were obtained from the PARAFAC calculations of the three sets of $\mathrm{HSs}_{\mathrm{BaP}}, \mathrm{FA}_{\mathrm{BaP}}, \mathrm{HA}_{\mathrm{BaP}}$ and, the reference spectra are obtained from the PARAFAC model of the three reference sets of HSs, FA and HA. This congruence coefficient allows the estimation of the modification of the spectral characteristics of the reference fluorophores from reference sets when pure BaP is added to the soil fractions. An $\mathrm{r}_{\mathrm{c}}=0.90$ indicates a high level of similarity, values higher than 0.95 indicate that the compared spectra are virtually identical.

\section{Results and Discussion}

3.1. Characterization of the Fluorescent Reference Components in HSs, FA and $H A$

The appropriate number of components resulting from PARAFAC model was determined by high values of CorConDia and by visual analysis of the spectra of the obtained components. The PARAFAC models tested with 3, 4 and 5 components were excluded because of the low values of CorConDia combined with inappropriate spectral shapes. The best PARAFAC test was obtained from the two-component model. Results showed the contribution of two fluorophores in each soil fraction with a CorConDia of 96\%, 94\% and 99\% for HSs, FA and HA respectively. Fig. 1 shows the spectra of two fluorophores present in the reference HSs, FA and HA. The spectral characteristics of the components $C_{1}$ and $\mathrm{C}_{2}$ present in HSs, FA and HA showed similarities with previous fluorophores reported in literature (Table 1 ). Component $\mathrm{C}_{1} \mathrm{HSs}$ and $\mathrm{C}_{1} \mathrm{FA}$ from this study had similar spectral characteristics with component 1 found in estuarine system by Singh et al. [51], and in aquatic environments by Stedmon et al [52] and by Nagao et al [54] and other works listed in Table 1 . Component $\mathrm{C}_{2} \mathrm{HSs}$ and $\mathrm{C}_{2} \mathrm{FA}$ were found similar to component 4 in estuary from Singh et al. [51] study and component 2 from Stedmon et al. and Stedmon and Markager works found in estuary and sea water respectively [42,55]. $\mathrm{C}_{1} \mathrm{HA}$ ( $\lambda$ ex/ $\mathrm{\lambda em}$ : 350/452 $\mathrm{nm}$ ) refers to humic-like component (C-peak) [24] in marine environment and to HA in coral reefs [56]. Component $\mathrm{C}_{2} \mathrm{HA}$ ( $\lambda$ ex/ $\mathrm{\lambda em:} \mathrm{460/(496)} 520$ $\mathrm{nm}$ ) refers to soil fulvic acid [52] in aquatic environment, to component 2 in whole soil and humin samples [38] to terrestrial HA and lignin derivatives [56] and to Aldrich HA [57].

We used similarity coefficient $\left(\mathrm{r}_{\mathrm{c}}\right.$ ) and visual observations (Fig. 2 ) to compare the similarity of the spectral characteristics between $\mathrm{C}_{1} \mathrm{HSs}$ and $\mathrm{C}_{1} \mathrm{FA}$ and between $\mathrm{C}_{2} \mathrm{HSs}$ and $\mathrm{C}_{2} \mathrm{FA}$. $\mathrm{C}_{1} \mathrm{HSs}$ and $\mathrm{C}_{1} \mathrm{FA}$ have similar PARAFAC excitation and emission loading spectra and recorded a congruence coefficient $r_{c}=0.996$ for both excitation and emission (Fig. $2 \mathrm{~A}$ ). The excitation spectra of $\mathrm{C}_{2} \mathrm{HSs}$ and $\mathrm{C}_{2} \mathrm{FA}$ recorded a similarity coefficient of 0.968; the peak of $\mathrm{C}_{2} \mathrm{HSs}$ maximum around $420 \mathrm{~nm}$ was broader than that of $\mathrm{C}_{2} \mathrm{FA}$ maximum at $400 \mathrm{~nm}$ (Fig. 2B). The emission spectra of these two components recorded a high similarity coefficient of 0.974 with a common peak at 490 and $487 \mathrm{~nm}$ respectively and a second peak at $520 \mathrm{~nm}$ for $\mathrm{C}_{2} \mathrm{HSs}$ which becomes a shoulder at $517 \mathrm{~nm}$ for $\mathrm{C}_{2}$ FA. Excitation and emission spectra of $\mathrm{C}_{1} \mathrm{HA}$ had similar shapes comparing to those of $\mathrm{C}_{1} \mathrm{HSs}$ and $\mathrm{C}_{1} \mathrm{FA}$ with a red shift around $20 \mathrm{~nm}$ (Fig.

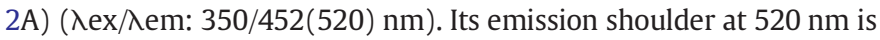
much more apparent than in $\mathrm{C}_{1} \mathrm{HSs}$ and $\mathrm{C}_{1} \mathrm{FA}(517 \mathrm{~nm})$.

As seen in Fig. 2B, $\mathrm{C}_{2} \mathrm{HA}$ had less similar excitation spectral loading to those of $\mathrm{C}_{2} \mathrm{HSs}\left(\mathrm{r}_{\mathrm{c}}=0.956\right)$ and $\mathrm{C}_{2} \mathrm{FA}\left(\mathrm{r}_{\mathrm{c}}=0.927\right)$. The similarity coefficients of the emission spectral loading of $\mathrm{C}_{2} \mathrm{HA}$ with the emission spectral loadings of $\mathrm{C}_{2} \mathrm{HSs}$ and $\mathrm{C}_{2} \mathrm{FA}$ were 0.966 and 0.942 respectively. The shoulder of $\mathrm{C}_{2} \mathrm{HA}$ ( $496 \mathrm{~nm}$ ) corresponded to common peaks in $\mathrm{C}_{2} \mathrm{HSs}$
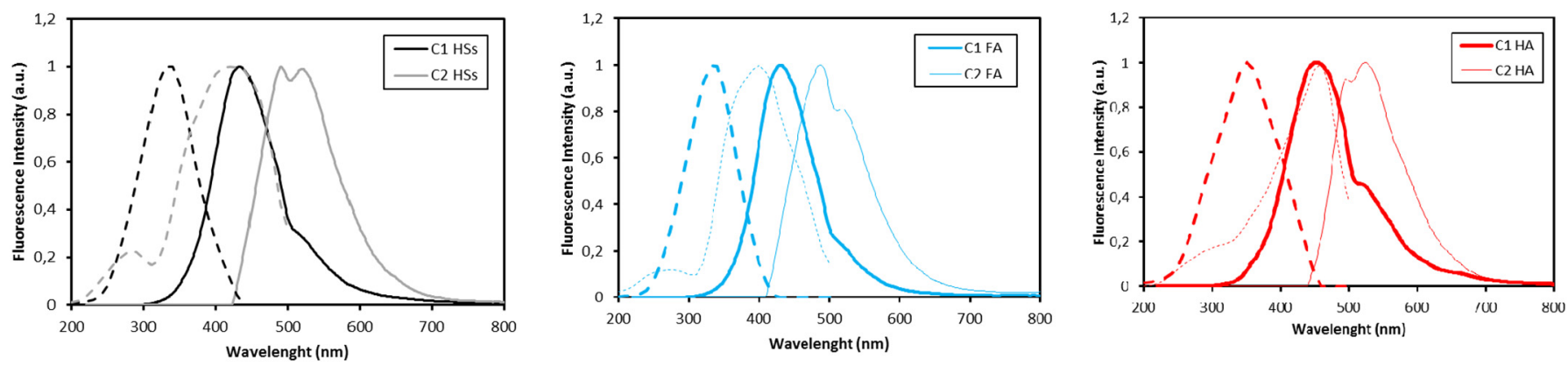

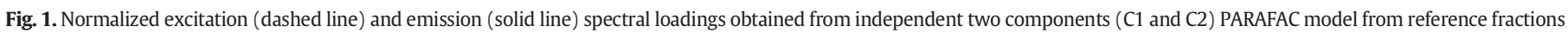
HSs, FA and HA. 
Table 1

Description of the components identified by PARAFAC analysis of reference HSs, FA and HA fractions of natural soil and comparison with previously identified fluorophores in literature.

\begin{tabular}{|c|c|c|}
\hline Component (this study) & $\mathrm{Ex} / \mathrm{Em}(\mathrm{nm})$ & References \\
\hline Component $\mathrm{C}_{1} \mathrm{HSs}$ & $330 / 433(520)$ & Component 1 [51] \\
\hline \multirow[t]{6}{*}{$\mathrm{C}_{1} \mathrm{FA}$} & \multirow[t]{6}{*}{$330 / 430(520)$} & Component 1 [52] \\
\hline & & Component 1 [53] \\
\hline & & Component 4 [42] \\
\hline & & Component 1 [32] \\
\hline & & Component 3 [22] \\
\hline & & FA [54] \\
\hline Component $\mathrm{C}_{2} \mathrm{HSs}$ & $420 / 490-520$ & Component 4 [51] \\
\hline \multirow[t]{2}{*}{$\mathrm{C}_{2} \mathrm{FA}$} & \multirow[t]{2}{*}{$400 / 487(517)$} & Component 2 [42] \\
\hline & & Component 2 [55] \\
\hline \multirow[t]{5}{*}{ Component $\mathrm{C}_{1} \mathrm{HA}$} & \multirow[t]{5}{*}{$350 / 452(520)$} & C-peak Humic-like [24] \\
\hline & & Component 3 [52] \\
\hline & & Component 1 [42] \\
\hline & & Component 1 [22] \\
\hline & & HA [56] \\
\hline \multirow[t]{5}{*}{ Component $\mathrm{C}_{2} \mathrm{HA}$} & \multirow[t]{5}{*}{$460 /(496) 520$} & Component 4 [54] \\
\hline & & Component 2 [38] \\
\hline & & E soil fulvic acid [52] \\
\hline & & Terrestrial HA [56] \\
\hline & & HA Aldrich [57] \\
\hline
\end{tabular}

(490 nm) and $\mathrm{C}_{2} \mathrm{FA}(497 \mathrm{~nm})$. The peak around $520 \mathrm{~nm}$ is common for $\mathrm{C}_{2} \mathrm{HSs}$ and $\mathrm{C}_{2} \mathrm{HA}$ while a shoulder was observed for $\mathrm{C}_{2} \mathrm{FA}$ at similar wavelength $(517 \mathrm{~nm})$. On the other hand, excitation and emission spectra of $\mathrm{C}_{2} \mathrm{HSs}$ seem to be a combination of those of $\mathrm{C}_{2} \mathrm{FA}$ and $\mathrm{C}_{2} \mathrm{HA}$.

\subsection{PARAFAC Decomposition of HSs, FA and HA Containing Pure BaP}

The best PARAFAC analysis applied to FEEMs of tested soil fractions with added $\mathrm{BaP}\left(\mathrm{HSs}_{\mathrm{BaP}}, \mathrm{FA}_{\mathrm{BaP}}\right.$ and $\left.\mathrm{HA}_{\mathrm{BaP}}\right)$ revealed the presence of three components (Fig. 3B). CorConDia scored $94 \%, 91 \%$ and $41 \%$ for PARAFAC decomposition of $\mathrm{HSs}_{\mathrm{BaP}}, \mathrm{FA}_{\mathrm{BaP}}$ and $\mathrm{HA}_{\mathrm{BaP}}$ respectively. Despite a weak CorConDia, the three factor PARAFAC model of $\mathrm{HA}_{\mathrm{BaP}}$ was validated because the spectral characteristics of the three components were consistent with those validated in $\mathrm{HSs}_{\mathrm{BaP}}$ and $\mathrm{FA}_{\mathrm{BaP}}$. The decompositions to more than three components did not score a high CorConDia percentage $(<40 \%)$.

The spectral characteristics of the three fluorophores found in $\mathrm{HSS}_{\mathrm{BaP}}$ and $\mathrm{FA}_{\mathrm{BaP}}$ are very similar with similarity coefficients above 0.950 . $\mathrm{C}_{1} \mathrm{HSS}_{\mathrm{BaP}}$ and $\mathrm{C}_{1} \mathrm{FA}_{\mathrm{BaP}}$ had their excitation and emission maxima $(\lambda \mathrm{ex} /$ $\lambda$ em) at $340 / 430 \mathrm{~nm}\left(\mathrm{r}_{\mathrm{c}}=0.996\right.$ for the excitation spectra and $\mathrm{r}_{\mathrm{c}}=$ 0.998 for the emission spectra) and $\mathrm{C}_{2} \mathrm{HSs}_{\mathrm{BaP}}$ and $\mathrm{C}_{2} \mathrm{FA}_{\mathrm{BaP}}$ had their maxima and (shoulder) at 400/(494) $525 \mathrm{~nm}$ and 400/(495) $526 \mathrm{~nm}$ respectively $\left(r_{c}=0.997\right.$ for the excitation spectra and $r_{c}=1$ for the emission spectra). $\mathrm{C}_{3} \mathrm{HSs}_{\mathrm{BaP}}$ and $\mathrm{C}_{3} \mathrm{FA}_{\mathrm{BaP}}$ had their $\lambda \mathrm{ex} / \lambda \mathrm{em}$ maxima at 290 $380 / 408-427 \mathrm{~nm}\left(\mathrm{r}_{\mathrm{c}}=0.999\right.$ for the excitation spectra and the emission spectra).

The spectral shape of component $C_{1} H_{A} A_{B a P}$ spectra ( $\lambda$ ex/ $/$ em: (360) $400 / 492-526 \mathrm{~nm}$ ) differ from those of $\mathrm{HSs}_{\mathrm{BaP}}$ and $\mathrm{FA}_{\mathrm{BaP}}$ with a red shift of around $60 \mathrm{~nm}$. $\mathrm{C}_{2} \mathrm{HA}_{\mathrm{BaP}}$ excitation spectrum (maxima at $\lambda$ ex: $470 \mathrm{~nm}$ ) differ from those of $\mathrm{C}_{2} \mathrm{HSS}_{\mathrm{Bap}}$ and $\mathrm{C}_{2} \mathrm{FA}_{\mathrm{BaP}}$ in shape and location and recorded a red shift of around $70 \mathrm{~nm}$. Whereas the emission spectrum of $\mathrm{C}_{2} \mathrm{HA}_{\mathrm{BaP}}$ ( $\lambda \mathrm{em}$ at (495)525 nm), was found similar to those found in $\mathrm{HSs}_{\mathrm{BaP}}$ and $\mathrm{FA}_{\mathrm{BaP}}$ having the same peak location but has a narrower shape, their similarity coefficient were 0.928 for $\mathrm{C}_{2} \mathrm{HSs}_{\mathrm{BaP}}$ and 0.926 for $\mathrm{C}_{2} \mathrm{FA}_{\mathrm{Bap}}$. The shape of the excitation and emission spectra of $\mathrm{C}_{3} \mathrm{HA}_{\mathrm{BaP}}$ are slightly modified comparing to those of $\mathrm{C}_{3} \mathrm{HSs}_{\mathrm{BaP}}$ and $\mathrm{C}_{3} \mathrm{FA}_{\mathrm{BaP}}$ and had maxima at $\lambda \mathrm{ex} / \mathrm{\lambda em}$ at 300-370/409-427 nm. The congruence coefficient $r_{c}$ of the excitation spectra of $\mathrm{C}_{3} \mathrm{HA}_{\mathrm{BaP}}$ with $\mathrm{C}_{3} \mathrm{HSs}_{\mathrm{BaP}}$ and $\mathrm{C}_{3} \mathrm{FA}_{\mathrm{BaP}}$ are scored 0.958 and 0.950 respectively and those of the emission spectra of $\mathrm{C}_{3} \mathrm{HA}_{\mathrm{BaP}}$ with $\mathrm{C}_{3} \mathrm{HSS}_{\mathrm{BaP}}$ and $\mathrm{C}_{3} \mathrm{FA}_{\mathrm{BaP}}$ scored 0.976 and 0.981 .

On the other hand, by comparison with the spectral properties of pure $\mathrm{BaP}\left(10^{-5} \mathrm{M}\right)$ in water, the third fluorophore $\left(\mathrm{C}_{3} \mathrm{HSs}_{\mathrm{BaP}}\right.$; $\mathrm{C}_{3} \mathrm{FA}_{\mathrm{BaP}} ; \mathrm{C}_{3} \mathrm{HA}_{\mathrm{BaP}}$ ) was identified as BaP. The similarity coefficient $\mathrm{r}_{\mathrm{C}}$ of the excitation spectral loading of components $\mathrm{C}_{3} \mathrm{HSs}_{\mathrm{BaP}}$ and $\mathrm{C}_{3} \mathrm{FA}_{\mathrm{BaP}}$ with that of pure BaP were 0.995 and 0.991 respectively and those of the emission spectral loadings were of 0.984 and 0.985 respectively. $\mathrm{C}_{3} \mathrm{HA}_{\mathrm{BaP}}$ was also identified as $\mathrm{BaP}$ having a similarity coefficient $\mathrm{r}_{\mathrm{c}}$ of 0.972 and 0.988 for the excitation and emission spectral loadings respectively.

Regardless of the high similarity coefficient between the spectral characteristics of $\mathrm{C}_{3} \mathrm{HA}_{\mathrm{BaP}}$ and pure BaP, it can be visually noticed that there are some deformations in the shape of $C_{3}$ spectral loadings in $\mathrm{HA}_{\mathrm{BaP}}$. That seems to reveal a modification of the spectral characteristics of $\mathrm{BaP}$ in $\mathrm{HA}_{\mathrm{BaP}}$ fraction.

Thus the presence of BaP affects the spectral characteristics of soil fractions conserving fluorescent feature of pure BaP in HS and FA fractions but not in HA fraction where fluorescence of BaP is modified compared to that of pure form.

Comparison of PARAFAC spectral loadings of reference components (Fig. $3 \mathrm{~A}$ ) resulting from the separate decomposition of HSs, FA and HA with those resulting from decomposition of $\mathrm{HSs}_{\mathrm{BaP}}, \mathrm{FA}_{\mathrm{BaP}}$ and $\mathrm{HA}_{\mathrm{BaP}}$ containing added pure $\mathrm{BaP}$ (Fig. $3 \mathrm{~B}$ ) shows that $\mathrm{BaP}$ modified the fluorescence features of each fraction differently.

For $C_{1}$, spectral modifications due to the addition of pure BaP are identical in HSs and FA fractions which have highly similar spectral characteristics as previously mentioned. It was noted that the resulting
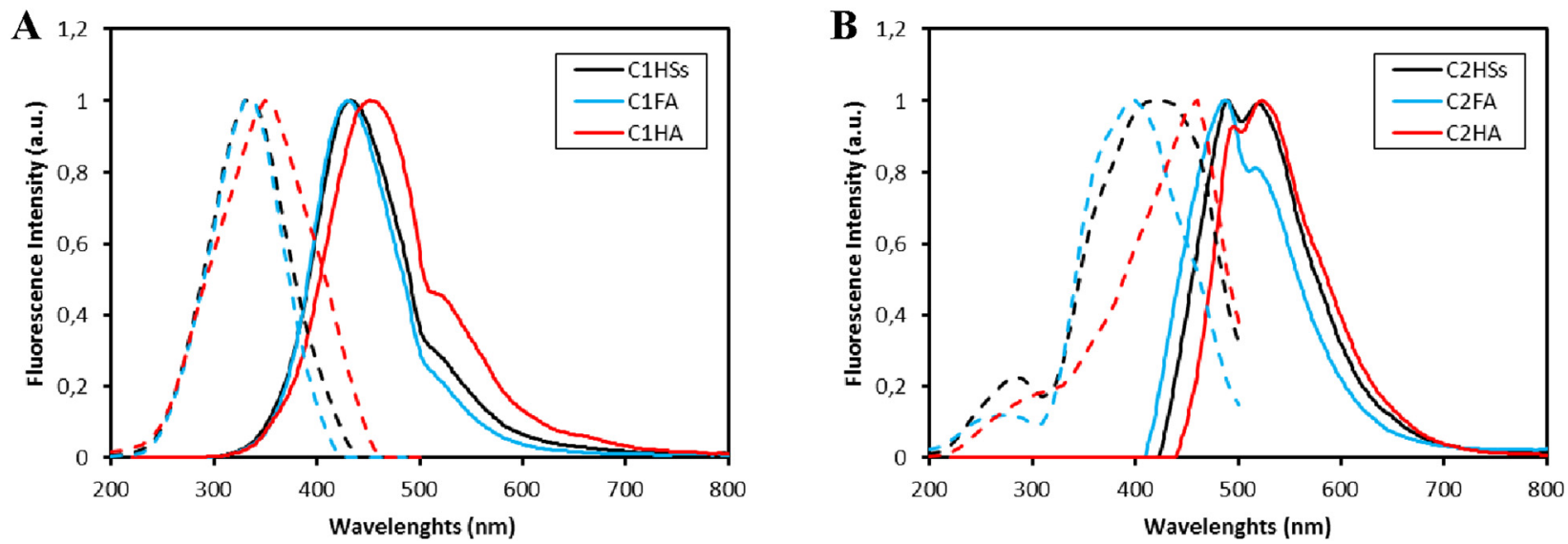

Fig. 2. Comparison of spectral characteristics of the obtained fluorophores ( $\mathrm{C} 1$ and $\mathrm{C} 2$ ) from two component PARAFAC model in HSs, FA and HA (normalized spectra). 
C1
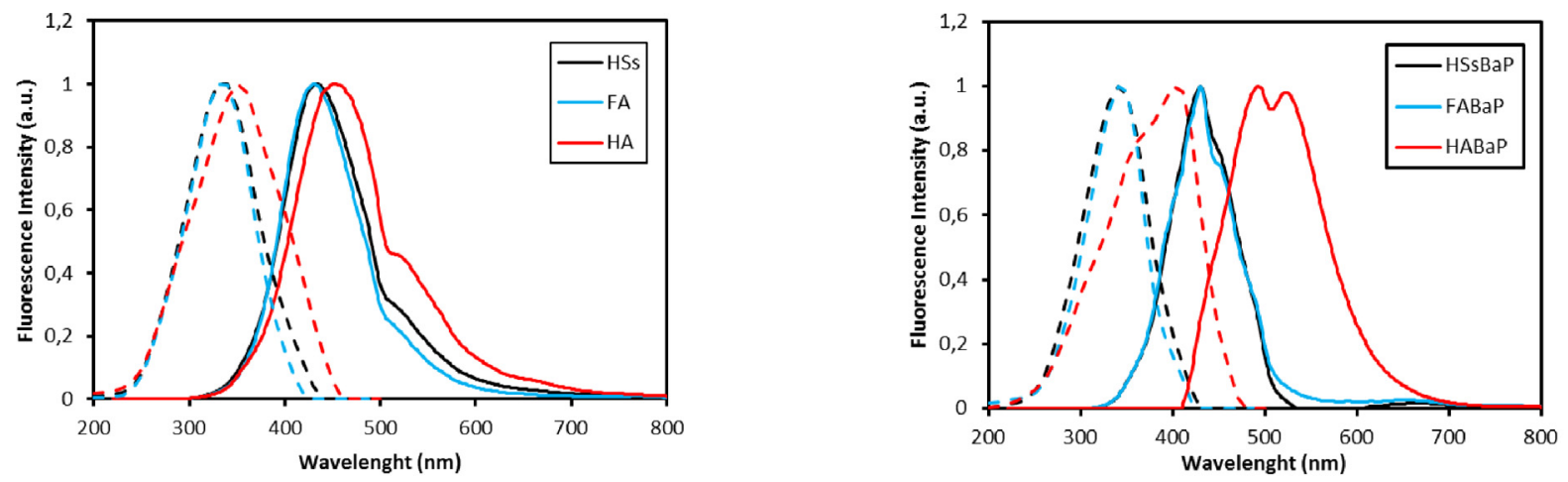

$\mathrm{C2}$
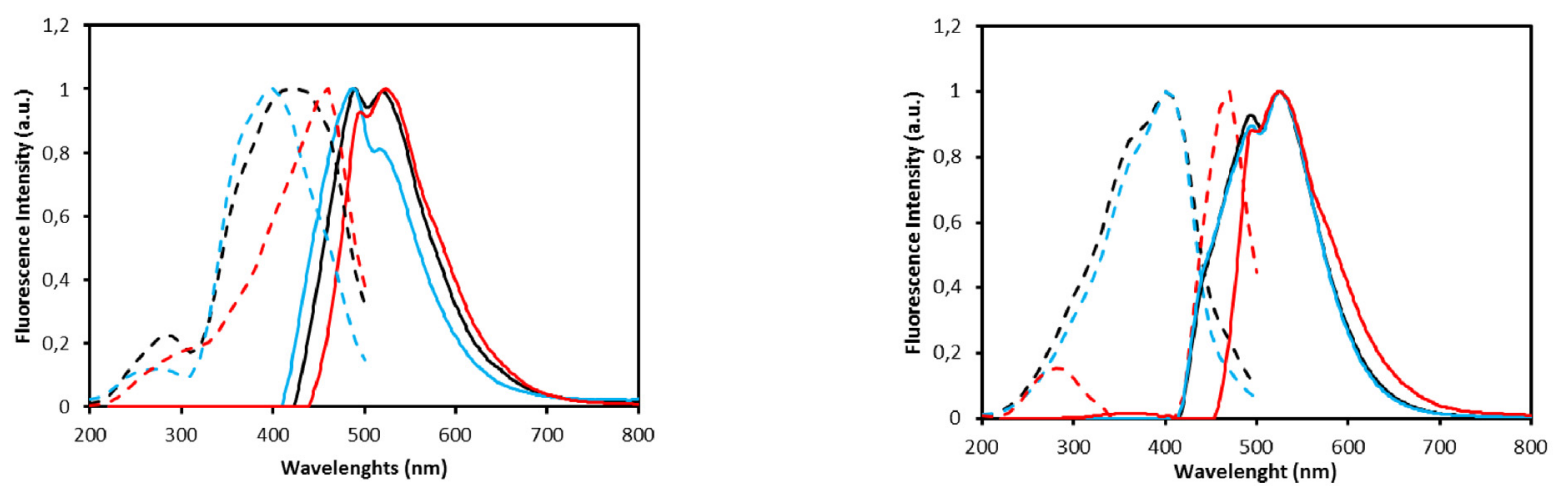

C3

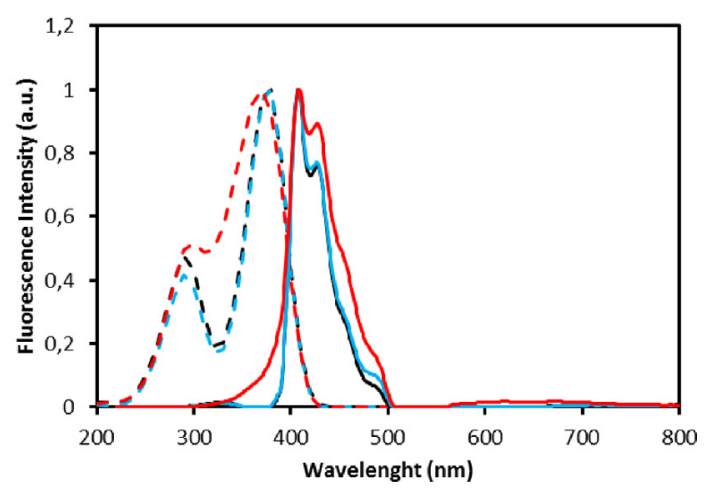

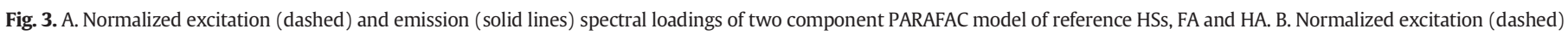
and emission (solid lines) spectral loadings of three-component PARAFAC model of $\mathrm{HSs}_{\mathrm{BaP}}, \mathrm{FA}_{\mathrm{BaP}}$ and $\mathrm{HA} \mathrm{BaP}_{\mathrm{Ba}}(\mathrm{C} 1$ : component 1, C2: component 2 and C3: component 3).

excitation spectra of $\mathrm{C}_{1} \mathrm{HSs}_{\mathrm{BaP}}$ and $\mathrm{C}_{1} \mathrm{FA}_{\mathrm{BaP}}$ were red shifted by $10 \mathrm{~nm}$ in comparison with those from the reference data sets $C_{1} H S$ and $C_{1} F A$. Despite the red shift and the modified shape, the excitation and emission spectral loading of components $\mathrm{C}_{1} \mathrm{HSS}_{\mathrm{BaP}}$ scored a congruence coefficient $r_{c}=0.995$ and $r_{c}=0.968$ with those of the reference $C_{1} H S$. Comparing the spectral loadings of $\mathrm{C}_{1} \mathrm{FA}_{\mathrm{BaP}}$ with those of the reference $C_{1} F A$, similarity coefficient $r_{c}$ recorded 0.990 for excitation and emission.

Comparing the spectral features of $\mathrm{C}_{1} \mathrm{HA}$ and $\mathrm{C}_{1} \mathrm{HA}_{\mathrm{BaP}}$, we noted a modification in the shape of the excitation and emission spectra of
$\mathrm{C}_{1} \mathrm{HA}_{\mathrm{BaP}}$ along with a red shift of $50 \mathrm{~nm}$ for the $\lambda$ ex and $40 \mathrm{~nm}$ for $\lambda$ em. The congruence coefficient $r_{c}$ of the compared excitation spectra was $r_{c}=0.910$ and that of the emission spectra recorded a lower value $\left(r_{c}=0.789\right)$ that was due to the appearance of the double peak (入em: 492-523 nm) (Fig. 3B).

Spectral characteristics of the excitation and emission loadings of components $\mathrm{C}_{2} \mathrm{HSs}_{\mathrm{BaP}}$ and $\mathrm{C}_{2} \mathrm{FA}_{\mathrm{BaP}}$ were also compared to those of $\mathrm{C}_{2} \mathrm{HSs}$ and of $\mathrm{C}_{2} \mathrm{FA}$. It was found that the emission spectral loadings of $\mathrm{C}_{2} \mathrm{HSs}_{\mathrm{BaP}}$ and $\mathrm{C}_{2} \mathrm{FA}_{\mathrm{BaP}}$ were similar to those of the reference and scored similarity coefficients $r_{c}=0.994$ and 0.980 respectively. The intensity of 
the peak around $490 \mathrm{~nm}$ decreased, while the intensity of the peak around $520 \mathrm{~nm}$ increased in $\mathrm{C}_{2} \mathrm{HSs}_{\mathrm{BaP}}$ and $\mathrm{C}_{2} \mathrm{FA}_{\mathrm{Bap}}$. The excitation spectral loadings of $\mathrm{C}_{2} \mathrm{HSs}_{\mathrm{BaP}}$ and $\mathrm{C}_{2} \mathrm{HSs}$ were less similar and had a similarity coefficient $r_{c}=0.903$, whereas those of $C_{2} F_{B} A_{B a P}$ and $C_{2} F A$ showed higher similarity and scored an $r_{c}=0.956$. It was also noticed that the $\lambda$ ex of $\mathrm{C}_{2} \mathrm{HSs}_{\mathrm{Bap}}$ had a blue shift of around $20 \mathrm{~nm}$ compared with $\lambda$ ex of $\mathrm{C}_{2} \mathrm{HSs}$ along with a modified shape.

In $\mathrm{HA}_{\mathrm{BaP}}$ fraction, the shape of the excitation spectra of $\mathrm{C}_{2} \mathrm{HA}_{\mathrm{BaP}}$ was modified and red shifted by $10 \mathrm{~nm}$ compared with that of $\mathrm{C}_{2} \mathrm{HA}$. Similarity coefficient of the excitation spectra of $\mathrm{C}_{2} \mathrm{HA}_{\mathrm{BaP}}$ and $\mathrm{C}_{2} \mathrm{HA}$ was weak $\left(r_{\mathrm{c}}=0.814\right)$. However, the addition of BaP had little effect on the emission spectrum of $\mathrm{C}_{2} \mathrm{HA}_{\mathrm{BaP}}$. It recorded a high similarity coefficient (0.980) with that of $\mathrm{C}_{2} \mathrm{HA}$.

These comparisons demonstrated that the presence of $\mathrm{BaP}$ seems to highly influence the fluorescence features of $C_{1}$ in $\mathrm{HA}$ fraction while the fluorescence characteristics of $C_{2}$ seem to be more affected by BaP in HSs and FA fractions.

\subsection{BaP Impact on the Fluorophores in Soil Fractions}

The influence of $\mathrm{BaP}$ on the fluorophores present in soil was studied through the addition of 100,200 and $300 \mu \mathrm{L}$ of pure $\mathrm{BaP}\left(10^{-5} \mathrm{M}\right)$ to 3 $\mathrm{mL}$ of HSs, FA and HA. Fig. 4 shows the relative scores of components from PARAFAC in the three tested fractions. The addition of BaP to HSs and FA led to a high increase in fluorescence intensity of $\mathrm{C}_{2} \mathrm{HSs}_{\mathrm{BaP}}$ $($ slope $=1713.4)$ and $\mathrm{C}_{2} \mathrm{FA}_{\mathrm{BaP}}($ slope $=1597.1)$. They had steeper slopes compared to those of $\mathrm{C}_{1} \mathrm{HSs}_{\mathrm{BaP}}$ (340.07) and $\mathrm{C}_{1} \mathrm{FA}_{\mathrm{BaP}}$ (133.82). The scores of $\mathrm{C}_{2} \mathrm{HA}_{\mathrm{BaP}}$ did not increase with the addition of $\mathrm{BaP}$ (slope $=74.372$ ). On the other hand, $\mathrm{C}_{1} \mathrm{HA}_{\mathrm{Bap}}$ recorded a high slope (1188.2). These results confirm the influence of BaP addition on fluorescence intensities increase of $C_{2}$ in $\mathrm{HSs}_{\mathrm{BaP}}$ and $\mathrm{FA} \mathrm{BaP}_{\mathrm{BP}}$ fractions and of $\mathrm{C}_{1}$ in $\mathrm{HA}_{\mathrm{BaP}}$ fraction. The behavior of $\mathrm{C}_{3}$, identified as $\mathrm{BaP}$, is logically related to the addition of pure $\mathrm{BaP}$ with a high increase of relative scores (slope $=1216.2$ ) in $\mathrm{HSs}_{\mathrm{BaP}}$ fraction. The behavior of $\mathrm{C}_{3} \mathrm{HSS}_{\mathrm{BaP}}$ is similar to the variation of $\mathrm{C}_{2} \mathrm{HSs}_{\mathrm{BaP}}$ ( slope $=1713.4$ ). In $\mathrm{FA}_{\mathrm{BaP}}$ data sets, the increase of $C_{3}$ relative scores is lower (slope $=617.5$ ) than that in $\mathrm{HSs}_{\mathrm{BaP}}$. This behavior of $\mathrm{C}_{3} \mathrm{FA}_{\mathrm{BaP}}$ shows a moderate variation compared to the high evolution of $\mathrm{C}_{2} \mathrm{FA}_{\mathrm{BaP}}$ ( slope $=1597.1$ ). The lowest increase of $\mathrm{C}_{3}$ relative scores is observed in $\mathrm{HA}_{\mathrm{BaP}}$ fraction (slope $=332.27$ ) which differs from the high variation of $\mathrm{C}_{1} \mathrm{HA}_{\mathrm{BaP}}$ ( slope $=1188.2$ ).

This attenuation of $C_{3}$ fluorescence intensities in $\mathrm{FA}_{\mathrm{BaP}}$ and mainly in $\mathrm{HA}_{\mathrm{BaP}}$ fractions could be due to interactions between BaP and these fractions. As reported in previous studies, HA was found to be a fluorescent quencher that can reduce the fluorescence intensity of PAHs such as phenanthrene, pyrene, anthracene [48], naphthalene [60] and fluoranthene [61]. So quenching effect could have caused the attenuation of

\section{$\mathrm{HSS}_{\mathrm{BaP}}$}

FA

$\mathrm{HA}_{\mathrm{BaP}}$
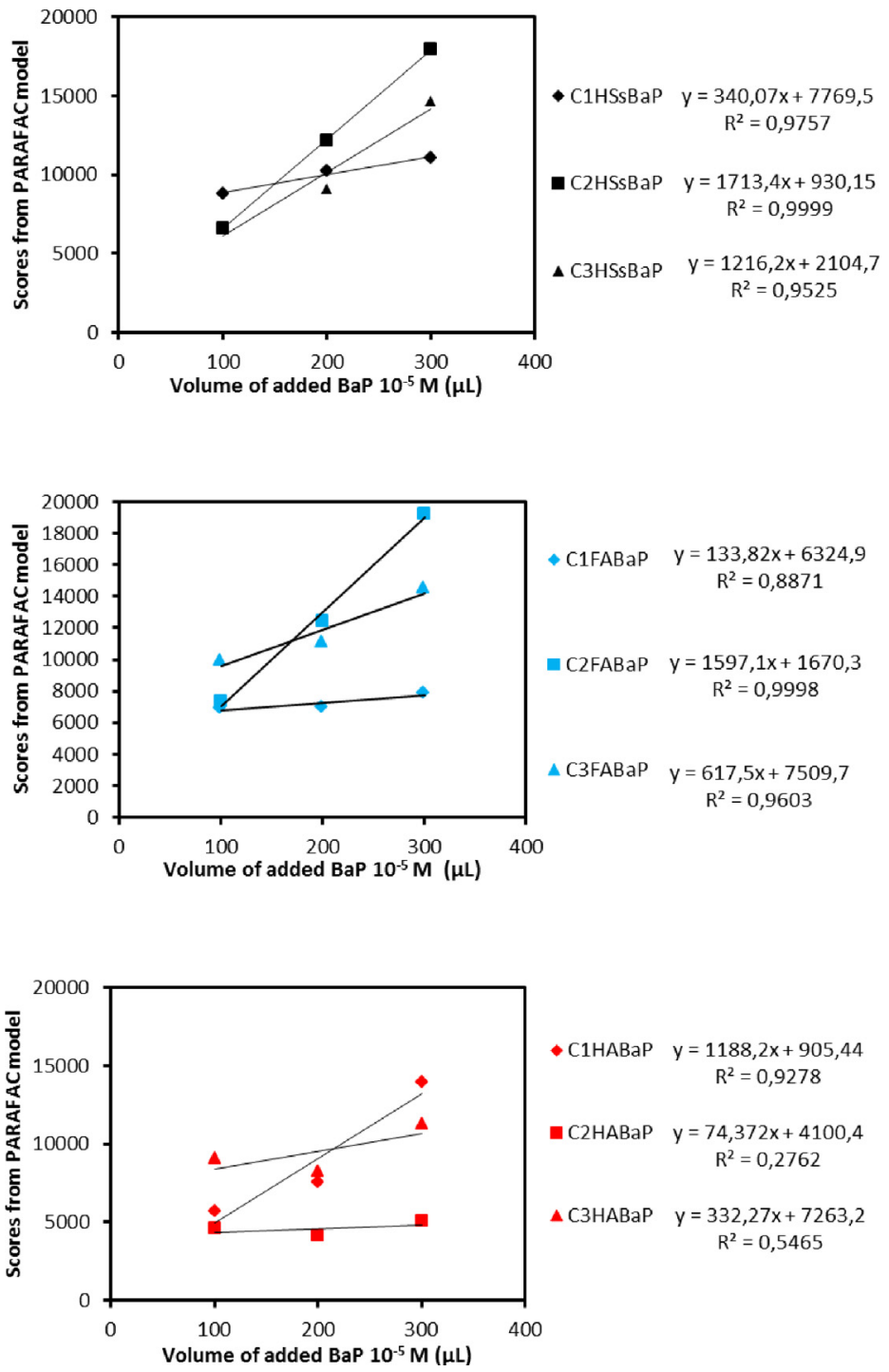
the fluorescence intensities of $\mathrm{C}_{3} \mathrm{HA}_{\mathrm{BaP}}$ in HA fraction in our study. Perhaps this phenomenon could have also occurred in a less intensive way in $\mathrm{FA}_{\mathrm{BaP}}$ fraction.

By taking into consideration the higher variations of fluorescence intensity of $\mathrm{C}_{2} \mathrm{HSs}, \mathrm{C}_{2} \mathrm{FA}$, and $\mathrm{C}_{1} \mathrm{HA}$ compared to those of $\mathrm{C}_{3} \mathrm{HSs}, \mathrm{C}_{3} \mathrm{FA}$, and $\mathrm{C}_{3} \mathrm{HA}$, it is possible to interpret these results as fluorescence resonance energy transfer (FRET). Superposition of the excitation and the emission spectra of pure $\mathrm{BaP}$ and those of the reference components present in HSs, FA and HA were carried out because the existence of overlaps between emission spectra of one component (energy donor) with the excitation spectra of another (energy acceptor) might induce energy transfer that in turn influences the fluorescence intensities. The fluorescence intensity of the energy donor shall decrease while that of the acceptor will increase. The superposition showed that the excitation

A

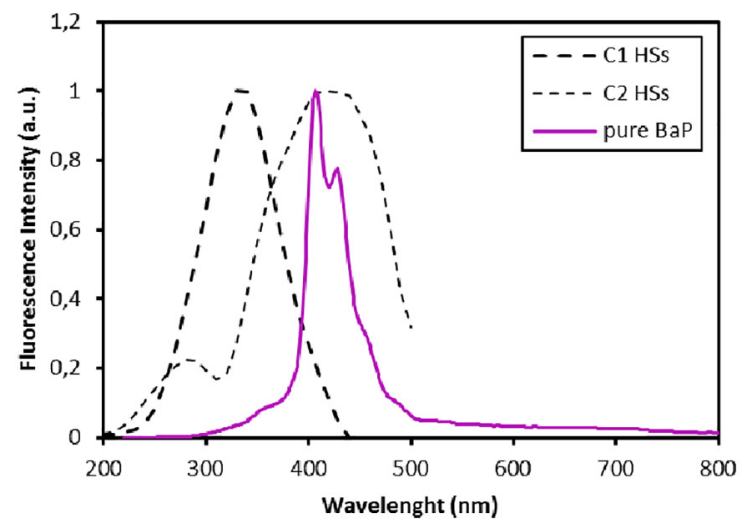

B

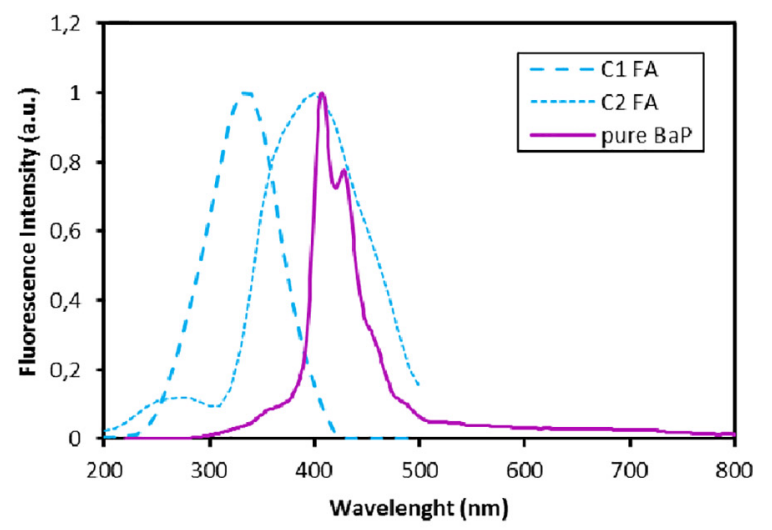

C

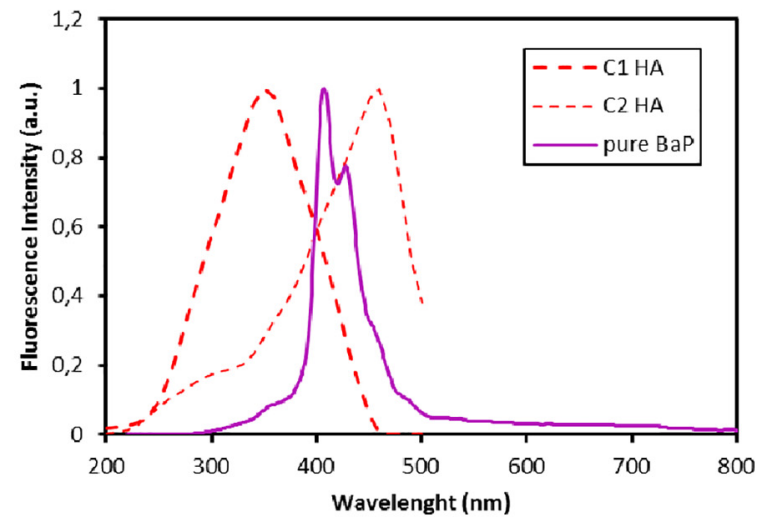

Fig. 5. Superposition of the normalized excitation spectra obtained from a two-component PARAFAC model of reference HSs, FA and HA fractions and the normalized emission spectra of pure BaP. spectra of components $\mathrm{C}_{2} \mathrm{HSs}$ and $\mathrm{C}_{2} \mathrm{FA}$ completely covers the emission spectra of pure $\mathrm{BaP}$ (Fig. 5A and $\mathrm{B}$ ). The energy from the emission of $\mathrm{BaP}$ (donor) might have been transferred to the excitation of $\mathrm{C}_{2} \mathrm{HSs}$ and $\mathrm{C}_{2} \mathrm{FA}$ (acceptors). It is also noted that the emission spectra of pure BaP overlaps the end of the excitation spectra of $\mathrm{C}_{1} \mathrm{HA}$, and the beginning of the excitation spectra of $\mathrm{C}_{2} \mathrm{HA}$ (Fig. $5 \mathrm{C}$ ). As only $\mathrm{C}_{1} \mathrm{HA}_{\mathrm{BaP}}$ fluorescence intensities increased (Fig. 4), this might propose that $\mathrm{C}_{1} \mathrm{HA}$ gained energy from the emission of pure BaP.

\section{Conclusion}

We studied by means of FEEMs-PARAFAC method, the spectral characteristics of the fluorescent components present in the SOM physical fractions HSs, FA and HA originating from a single soil sample. Then we investigated their spectral properties upon the addition of pure $\mathrm{BaP}$ solution to obtain new information regarding the interactions of $\mathrm{BaP}$ with these fluorophores.

HSs and FA fractions had one component (C1) highly similar. Upon addition of pure $\mathrm{BaP}$ solution component $\mathrm{C}_{2} \mathrm{HSs}$ and $\mathrm{C}_{2} \mathrm{FA}$ recorded similar spectral modifications.

Increasing the added volume of pure BaP solution allowed us to evaluate the variations of the scores resulting from PARAFAC model. These scores variations were also similar for HSs and FA fraction. We noticed that the scores of $\mathrm{C}_{2} \mathrm{HSs}$ and $\mathrm{C}_{2} \mathrm{FA}$ increased when the volume of added pure $\mathrm{BaP}$ solution increased.

The fluorophores present in HA fraction did not show high similarity with those present in HSs and FA except for the emission of $\mathrm{C}_{2} \mathrm{HA}$ that was quite close to those of $\mathrm{C}_{2} \mathrm{HSs}$ and $\mathrm{C}_{2} \mathrm{FA}$. The addition of pure BaP solution resulted in spectral modification of component $\mathrm{C}_{1} \mathrm{HA}$ and when the volume of $\mathrm{BaP}$ increased, the scores of this fluorophore increased as well.

The superposition of the excitation spectral loadings of $\mathrm{C} 1$ and $\mathrm{C} 2$ with the emission spectra of $\mathrm{BaP}$ in this study showed that $\mathrm{BaP}$ might be an energy donor and $\mathrm{C}_{2} \mathrm{HSs}, \mathrm{C}_{2} \mathrm{FA}$, and $\mathrm{C}_{1} \mathrm{HA}$ might be energy acceptors. Further complementary analysis using time-resolved fluorescence technique could support these observations.

This work showed that MEEFs-PARAFAC method can be applied for monitoring the quality of soils and for evaluating of the fate of polycyclic aromatic hydrocarbon such as benzo(a)pyrene in the humic substances, fulvic acid and humic acid.

\section{Acknowledgments}

Funding for this research was supported by the PEACE Erasmus Mundus Lot 2 Project No. 2012-2618/001-001-EMA2.

\section{References}

[1] M. Lee, Analytical Chemistry of Polycyclic Aromatic Compounds, Elsevier Science, Burlington, 2012.

[2] R.G. Harvey, Polycyclic Aromatic Hydrocarbons, Wiley [u.a.], New York, 1997.

[3] B. Armstrong, C. Tremblay, D. Baris, G. Thériault, Lung cancer mortality and polynuclear aromatic hydrocarbons: a case-cohort study of aluminum production workers in Arvida, Quebec, Canada, Am. J. Epidemiol. 139 (1994) 250-262.

[4] W.B. Wilson, B. Alfarhani, A.F.T. Moore, C. Bisson, S.A. Wise, A.D. Campiglia, Determination of high-molecular weight polycyclic aromatic hydrocarbons in high performance liquid chromatography fractions of coal tar standard reference material 1597a via solid-phase nanoextraction and laser-excited time-resolved Shpol'skii spectroscopy, Talanta 148 (2016) 444-453, https://doi.org/10.1016/j.talanta.2015. 11.018.

[5] M.S. García Falcón, S. González Amigo, M.A. Lage Yusty, J. Simal Lozano, Determination of benzo[a]pyrene in some Spanish commercial smoked products by HPLC-FL, Food Addit. Contam. 16 (1999) 9-14, https://doi.org/10.1080/026520399284271.

[6] L. Luo, S. Zhang, Y. Ma, Evaluation of impacts of soil fractions on phenanthrene sorption, Chemosphere 72 (2008) 891-896, https://doi.org/10.1016/j.chemosphere. 2008.03.051.

[7] F.J. Stevenson, Humus Chemistry: Genesis, Composition, Reactions, 2nd ed. Wiley, New York, 1994.

[8] W. Zech, N. Senesi, G. Guggenberger, K. Kaiser, J. Lehmann, T.M. Miano, A. Miltner, G. Schroth, Factors controlling humification and mineralization of soil organic matter 
in the tropics, Geoderma 79 (1997) 117-161, https://doi.org/10.1016/S0016-7061 (97)00040-2

[9] M. Klučáková, Characterization of pH-fractionated humic acids with respect to their dissociation behaviour, Environ. Sci. Pollut. Res. 23 (2016) 7722-7731, https://doi. org/10.1007/s11356-015-5932-2.

[10] M.M. Kononova, Soil Organic Matter: Its Nature, Its Role in Soil Formation and in Soil Fertility, Elsevier Science, Burlington, 2013http://public.eblib.com/choice/ publicfullrecord.aspx? $\mathrm{p}=1817599$, Accessed date: 3 May 2017

[11] S. Bratskaya, A. Golikov, T. Lutsenko, O. Nesterova, V. Dudarchik, Charge characteristics of humic and fulvic acids: comparative analysis by colloid titration and potentiometric titration with continuous pK-distribution function model, Chemosphere 73 (2008) 557-563, https://doi.org/10.1016/j.chemosphere.2008.06.014.

[12] T. Michałowski, A.G. Asuero, New approaches in modeling carbonate alkalinity and total alkalinity, Crit. Rev. Anal. Chem. 42 (2012) 220-244, https://doi.org/10.1080/ 10408347.2012.660067.

[13] K.H. Tan, Humic Matter in Soil and the Environment: Principles and Controversies, second edition CRC Press, Taylor \& Francis Group, Boca Raton, FL, 2014.

[14] V. Hernández-Montoya, L.H. Alvarez, M.A. Montes-Morán, F.J. Cervantes, Reduction of quinone and non-quinone redox functional groups in different humic acid samples by Geobacter sulfurreducens, Geoderma 183-184 (2012) 25-31, https://doi. org/10.1016/j.geoderma.2012.03.007.

[15] S. Huang, Y. Wang, L. Cao, K. Pi, M. Yu, E. Even, Multidimensional spectrofluorometry characterization of dissolved organic matter in arsenic-contaminated shallow groundwater, J. Environ. Sci. Health, Part A 47 (2012) 1446-1454, https://doi.org/ $10.1080 / 10934529.2012 .672390$

[16] J.J. Pignatello, Soil organic matter as a nanoporous sorbent of organic pollutants, Adv. Colloid Interf. Sci. 76-77 (1998) 445-467, https://doi.org/10.1016/S00018686(98)00055-4.

[17] X. Oiu, S.I. Shah, E.W. Kendall, D.L. Sorensen, R.C. Sims, M.C. Engelke, Grass-enhanced bioremediation for clay soils contaminated with polynuclear aromatic hydrocarbons, in: T.A. Anderson, J.R. Coats (Eds.), Bioremediation Rhizosphere Technol. American Chemical Society, Washington, DC 1994, pp. 142-157, https:// doi.org/10.1021/bk-1994-0563.ch013 (accessed March 20, 2017).

[18] J.F. McCarthy, L.E. Roberson, L.W. Burrus, Association of benzo(a)pyrene with dissolved organic matter: prediction of Kdom from structural and chemical properties of the organic matter, Chemosphere 19 (1989) 1911-1920, https://doi.org/10.1016/ 0045-6535(89)90014-3.

[19] P.F. Landrum, S.R. Nihart, B.J. Eadie, L.R. Herche, Reduction in bioavailability of organic contaminants to the amphipod Pontoporeia hoyi by dissolved organic matter of sediment interstitial waters, Environ. Toxicol. Chem. 6 (1987) 11-20, https:// doi.org/10.1002/etc.5620060102.

[20] M. Haitzer, B.K. Burnison, S. Höss, W. Traunspurger, C.E.W. Steinberg, Effects of quantity, quality, and contact time of dissolved organic matter on bioconcentration of benzo[a]pyrene in the nematode Caenorhabditis elegans, Environ. Toxicol. Chem. 18 (1999) 459-465, https://doi.org/10.1002/etc.5620180314.

[21] C. Chen, J. Rubao, J.D. Schwab, D. Beletsky, L.G. Fahnenstiel, M. Jiang, T.H. Johengen, H. Vanderploeg, B. Eadie, J. Wells Budd, M.H. Bundy, W. Gardner, J. Cotner, P.J. Lavrentyev, A model study of the coupled biological and physical dynamics in Lake Michigan, Ecol. Model. 152 (2002) 145-168.

[22] T. Ohno, R. Bro, Dissolved organic matter characterization using multiway spectral decomposition of fluorescence landscapes, Soil Sci. Soc. Am. J. 70 (2006) 2028, https://doi.org/10.2136/sssaj2006.0005.

[23] P.G. Coble, S.A. Green, N.V. Blough, R.B. Gagosian, Characterization of dissolved organic matter in the Black Sea by fluorescence spectroscopy, Nature 348 (1990) 432-435, https://doi.org/10.1038/348432a0.

[24] P.G. Coble, Characterization of marine and terrestrial DOM in seawater using excitation-emission matrix spectroscopy, Mar. Chem. 51 (1996) 325-346, https://doi.org/ 10.1016/0304-4203(95)00062-3.

[25] A. Baker, Fluorescence excitation-emission matrix characterization of some sewageimpacted rivers, Environ. Sci. Technol. 35 (2001) 948-953, https://doi.org/10.1021/ es000177t.

[26] J. Chen, E.J. LeBoeuf, S. Dai, B. Gu, Fluorescence spectroscopic studies of natural organic matter fractions, Chemosphere 50 (2003) 639-647, https://doi.org/10.1016/ S0045-6535(02)00616-1.

[27] T. Marhaba, V. Doanh, R.L. Lippincott, Rapid identification of dissolved organic matter fractions in water by spectral fluorescent signatures, Water Res. 34 (2000) 3543-3550, https://doi.org/10.1016/S0043-1354(00)00090-7.

[28] T.F. Marhaba, Fluorescence technique for rapid identification of DOM fractions, J. Environ. Eng. 126 (2000) 145-152, https://doi.org/10.1061/(ASCE)0733-9372(2000) 126:2(145)

[29] J. Chen, B. Gu, E.J. LeBoeuf, H. Pan, S. Dai, Spectroscopic characterization of the structural and functional properties of natural organic matter fractions, Chemosphere 48 (2002) 59-68, https://doi.org/10.1016/S0045-6535(02)00041-3.

[30] J. Gao, C. Liang, G. Shen, J. Lv, H. Wu, Spectral characteristics of dissolved organic matter in various agricultural soils throughout China, Chemosphere 176 (2017) 108-116, https://doi.org/10.1016/j.chemosphere.2017.02.104.

[31] M.M.D. Sierra, M. Giovanela, E. Parlanti, E.J. Soriano-Sierra, Fluorescence fingerprint of fulvic and humic acids from varied origins as viewed by single-scan and excitation/emission matrix techniques, Chemosphere 58 (2005) 715-733, https://doi org/10.1016/j.chemosphere.2004.09.038.

[32] R.D. Holbrook, J.H. Yen, T.J. Grizzard, Characterizing natural organic material from the Occoquan Watershed (Northern Virginia, US) using fluorescence spectroscopy and PARAFAC, Sci. Total Environ. 361 (2006) 249-266, https://doi.org/10.1016/j. scitotenv.2005.11.020

[33] R.G.M. Spencer, L. Bolton, A. Baker, Freeze/thaw and pH effects on freshwater dissolved organic matter fluorescence and absorbance properties from a number of
UK locations, Water Res. 41 (2007) 2941-2950, https://doi.org/10.1016/j.watres. 2007.04.012.

[34] J.L. Beltrán, R. Ferrer, J. Guiteras, Multivariate calibration of polycyclic aromatic hydrocarbon mixtures from excitation-emission fluorescence spectra, Anal. Chim. Acta 373 (1998) 311-319, https://doi.org/10.1016/S0003-2670(98) 00420-6.

[35] N. Ferretto, M. Tedetti, C. Guigue, S. Mounier, R. Redon, M. Goutx, Identification and quantification of known polycyclic aromatic hydrocarbons and pesticides in complex mixtures using fluorescence excitation-emission matrices and parallel facto analysis, Chemosphere 107 (2014) 344-353, https://doi.org/10.1016/j. chemosphere.2013.12.087.

[36] R.D. Jiji, G.A. Cooper, K.S. Booksh, Excitation-emission matrix fluorescence based determination of carbamate pesticides and polycyclic aromatic hydrocarbons, Anal Chim. Acta 397 (1999) 61-72, https://doi.org/10.1016/S0003-2670(99)00392-X.

[37] C.H. Santos, G. Nicolodelli, R.A. Romano, A.M. Tadini, P.R. Villas-Boas, C.R. Montes, S Mounier, D.M.B.P. Milori, Structure of humic substances from some regions of the Amazon assessed coupling 3D fluorescence spectroscopy and CP/PARAFAC, J. Braz Chem. Soc. (2015)https://doi.org/10.5935/0103-5053.20150076.

[38] A.M. Tadini, G. Nicolodelli, S. Mounier, C.R. Montes, D.M.B.P. Milori, The importance of humin in soil characterisation: a study on Amazonian soils using different fluorescence techniques, Sci. Total Environ. 537 (2015) 152-158, https://doi.org/10.1016/j. scitotenv.2015.07.125.

[39] R.A. Harshman, Foundations of the PARAFAC procedure: models and conditions for an "explanatory" multimodal factor analysis, UCLA Work. Pap. Phon. 161970 pp. 1-84.

[40] R. Bro, H.A.L. Kiers, A new efficient method for determining the number of components in PARAFAC models, J. Chemom. 17 (2003) 274-286, https://doi.org/10.1002/ cem.801.

[41] C.A. Stedmon, R. Bro, Characterizing dissolved organic matter fluorescence with parallel factor analysis: a tutorial: fluorescence-PARAFAC analysis of DOM, Limnol. Oceanogr. Methods 6 (2008) 572-579, https://doi.org/10.4319/lom.2008.6.572.

[42] C.A. Stedmon, S. Markager, Resolving the variability in dissolved organic matte fluorescence in a temperate estuary and its catchment using PARAFAC analysis, Limnol. Oceanogr. 50 (2005) 656-697.

[43] C.M. Andersen, R. Bro, Practical aspects of PARAFAC modeling of fluorescence excitation-emission data, J. Chemom. 17 (2003) 200-215, https://doi.org/10.1002/ cem.790.

[44] R. Bro, PARAFAC. Tutorial and applications, Chemom. Intell. Lab. Syst. 38 (1997) 149-171

[45] A.M. Tadini, H. Hajjoul, G. Nicolodelli, S. Mounier, C.R. Montes, D.M.B.P. Milori, Characterization of organic matter in spodosol amazonian by fluorescence spectroscopy World Acad. Sci. Eng. Technol. Int. Sci. Index 125, International J. Environ. Chem. Ecol. Geol. Geophys. Eng., vol. 11, 2017, pp. 322-325.

[46] W.-D. Guo, L.-Y. Yang, F.-L. Wang, W.-Z. Chen, X.-H. Wang, H.-S. Hong, Parallel factor analysis for excitation emission matrix fluorescence spectroscopy of dissolved organic matter from a reservoir-type river, Guang Pu Xue Yu Guang Pu Fen Xi Guang Pu 31 (2011) 427-430.

[47] M.L. Nahorniak, K.S. Booksh, Excitation-emission matrix fluorescence spectroscopy in conjunction with multiway analysis for PAH detection in complex matrices, Analyst 131 (2006) 1308, https://doi.org/10.1039/b609875d.

[48] R. Yang, N. Zhao, X. Xiao, S. Yu, J. Liu, W. Liu, Determination of polycyclic aromatic hydrocarbons by four-way parallel factor analysis in presence of humic acid Spectrochim. Acta A Mol. Biomol. Spectrosc. 152 (2016) 384-390, https://doi.org/ 10.1016/j.saa.2015.07.094.

[49] P. Duchaufour, F. Jacquin, Nouvelles recherches sur l'extraction et le fractionnement des composes humiques, Bull. E.N.S.A. (1966) 3-24.

[50] C. Ratsimbazafy, Protocole de fractionnement et d'étude de la matière organique des sols hydromorphes de Madagascar, Cah. ORSTOMSérie, Pédologie 11 (1973) 227-236.

[51] S. Singh, E.J. D'Sa, E.M. Swenson, Chromophoric dissolved organic matter (CDOM) variability in Barataria Basin using excitation-emission matrix (EEM) fluorescence and parallel factor analysis (PARAFAC), Sci. Total Environ. 408 (2010) 3211-3222, https://doi.org/10.1016/j.scitotenv.2010.03.044.

[52] C.A. Stedmon, S. Markager, R. Bro, Tracing dissolved organic matter in aquatic environments using a new approach to fluorescence spectroscopy, Mar. Chem. 82 (2003) 239-254, https://doi.org/10.1016/S0304-4203(03)00072-0.

[53] R.M. Cory, D.M. McKnight, Fluorescence spectroscopy reveals ubiquitous presence of oxidized and reduced quinones in dissolved organic matter, Environ. Sci. Technol. 39 (2005) 8142-8149, https://doi.org/10.1021/es0506962.

[54] S. Nagao, T. Matsunaga, Y. Suzuki, T. Ueno, H. Amano, Characteristics of humic substances in the Kuji River waters as determined by high-performance size exclusion chromatography with fluorescence detection, Water Res. 37 (2003) 4159-4170 https://doi.org/10.1016/S0043-1354(03)00377-4.

55] C.A. Stedmon, D.N. Thomas, M. Granskog, H. Kaartokallio, S. Papadimitriou, H. Kuosa Characteristics of dissolved organic matter in Baltic Coastal Sea Ice: allochthonous or autochthonous origins? Environ. Sci. Technol. 41 (2007) 7273-7279, https://doi org/10.1021/es071210f.

[56] B.J.H. Matthews, A.C. Jones, N.K. Theodorou, A.W. Tudhope, Excitation-emission-matrix fluorescence spectroscopy applied to humic acid bands in coral reefs, Mar. Chem. 55 (1996) 317-332, https://doi.org/10.1016/S0304-4203(96)00039-4.

[57] S. Nagao, Y. Suzuki, Y. Nakaguchi, M. Senoo, K. Hiraki, Direct measurement of the fluorescence characteristics of aquatic humic substances by a three-dimensiona fluorescence spectrophotometer, Bunseki Kagaku 46 (1997) 335-342, https://doi. org/10.2116/bunsekikagaku.46.335.

[58] R.G. Zepp, W.M. Sheldon, M.A. Moran, Dissolved organic fluorophores in southeastern US coastal waters: correction method for eliminating Rayleigh and Raman 
scattering peaks in excitation-emission matrices, Mar. Chem. 89 (2004) 15-36, https://doi.org/10.1016/j.marchem.2004.02.006.

[59] L.R. Tucker, A Method for the Synthesis of Factor Analysis Studies, Department of the Army, Washington, D.C., 1951

[60] M.J. Morra, M.O. Corapcioglu, R.M.A. von Wandruszka, D.B. Marshall, K. Topper, Fluorescence quenching and polarization studies of naphthalene and 1-naphthol interaction with humic acid, Soil Sci. Soc. Am. J. 54 (1990) 1283, https://doi.org/ 10.2136/sssaj1990.03615995005400050014x.

[61] S. Chen, W.P. Inskeep, S.A. Williams, P.R. Callis, Fluorescence lifetime measurements of fluoranthene, 1-naphthol, and napropamide in the presence of dissolved humic acid, Environ. Sci. Technol. 28 (1994) 1582-1588, https://doi.org/10.1021/ es00058a008. 